\title{
ASSISTÊNCIA DE ENFERMAGEM EM SERVIÇO PRÉ-HOSPITALAR E REMOÇÃO AEROMÉDICA
}

\author{
Patrícia Kuerten Rocha* \\ Marta Lenise do Prado** \\ Vera Radünz $z^{\star \star \star}$ \\ Antônio de Miranda Wosny****
}

\section{Resumo}

Trata o presente artigo de um relato de experiência desenvolvida durante a realização do Trabalho de Conclusão de Curso de Enfermagem da Universidade Federal de Santa Catarina, no segundo semestre de 2000 Discute a importância do Serviço de Atendimento Pré-hospitalar e Remoção Aeromédica e a necessidade de preparação da Enfermagem para atender as demandas crescentes desses serviços. Apresenta uma revisão histórica destas formas de atenção á saúde no Brasil e no mundo. Discute alguns aspectos relacionados a administração dos recursos humanos e materiais, no tocante a sua especificidade em serviços dessa natureza. Por fim, aponta para a importância do papel do Enfermeiro, bem como da necessária ampliação de suas competências para atuação na área de atendimento préhospitalar e remoção aeromédica.

Descritores: enfermagem; emergência préhospitalar; remoção aeromédica

\section{Abstract}

The present article is a description of an experience developed during the Conclusive Monography of the Nursing Course from Santa Catarina's Federal University, in the second semester year 2000. It discuss the importance of the Pre-hospital Attendiment Service and Airmedical Removal, and the need of nurses preparation to atend the increasing requests of those services. It presents a historical review on these kind of atention method in health, in Brazil and in the world. It discuss some aspects related to management of human and material resources, concerning its specificity in those kind of services. It also points out the importance of the Nurse roll, and the necessity of widing theirs skills to act in the field of prehospital attendiment and airmedical removal. Descriptors: nursing; pre-hospital emergency; airmedical removal

Title: Nursing Care in Pre-hospital Attendiment Service and Airmedical Removal

\section{Resumen}

Trata o presente artículo de un relato de experiencia desarolado durante la realización del Trabajo de Conclusión de Curso de Pregrado en Enfermería. Discute a importancia de lo Servicio de Asistencia pré-hospitalaria e remoción aeromedica, bem como la necesidad de la preparación de los profisionales de la enfermería para atender las demanda crecientes de estos servicios. Presenta uma revisión historica de esta forma de atención a la salud en Brasil y en mundo. Discute algunos aspectos relacionados a la administración de los recursos humano y materiales, no tocante a su especificidad en los servicios préhospitalarios. Por fin aponta la importancia del rol del enfermero y la necesaria ampliación de sus competencias para la atuación em la area de atendimento pre-hospitalario e remoción aeromédica.

Descriptores: enfermería; emergencia préhospitalaria; remoción aeromedica

Título: Asistencia de Enfermería en Servicio Pré-hospitalario y Remoción Aeromedica

\section{Introdução}

$O$ atendimento de emergência surgiu da necessidade da retirada e assistência de combatentes feridos em campos de batalha. Concebido pelas guerras, foi também a partir destas que desenvolveu-se, inicialmente, com o emprego de transportes de tração animal, chegando, na atualidade, ao emprego de sofisticados aparelhos e veículos de locomoção aéreo ou terrestre. Atualmente, este tipo de assistência apresenta maior importância no atendimento à população civil, carente de cuidados médicos imediatos, no transcorrer do seu cotidiano.

A emergência pré-hospitalar objetiva atender o cliente de forma sistematizada e prática, implicando, assim, necessidade de uma equipe multidisciplinar que promova um rápido atendimento e transporte do paciente a um centro de atendimento adequado à saúde.

Reconhecendo as lacunas na formação e a importância do tema, esse estudo teve como objetivo, entre outros, de prestar assistência de enfermagem à clientela em serviço de emergência pré-hospitalar (transporte e resgate terrestre) e remoção aérea, buscando conhecer aspectos relacionados com a organização dos recursos humanos e materiais de um serviço desta natureza.
Em virtude da grande prevalência de intercorrências que necessitam de um atendimento emergencial e ao grande impacto sócio-econômico destas situações que atingem, principalmente, a população economicamente ativa, torna-se imprescindível a busca constante de avanços nesta área, minimizando, assim, as conseqüências destas circunstâncias.

\section{Emergência pré-hospitalar, remoção aérea e a assistência de Enfermagem}

Ferreira conceitua emergência como uma situação crítica, acontecimento perigoso ou fortuito, incidente.

Em uma emergência, a Enfermagem deve estabelecer prioridades de assistência de acordo com a avaliação preliminar, garantindo assim a identificação e o tratamento das situações que ameaçam a vida do paciente. De forma que consideramos relevante que a enfermeira de emergência tenha presente, nesta situação, arte, habilidade, conhecimento, emoção, sentido; vivencie e compartilhe informações para um processo rápido, preciso, hábil e eficiente ao prestar assistência de Enfermagem. Além de prestar uma assistência globalizada ao ser humano e família(2).

O tempo que transcorre da hora do trauma até os primeiros procedimentos tem sido considerado um fator crítico.

* Enfermeira. Especialista em Enfermagem em Emergência e Aluna da Especialização Modalidade Residência em Enfermagem UTI Pediátrica na UNIFESP.

** Enfermeira. Doutora em Enfermagem, Docente do Departamento de Enfermagem e do Programa de Pós-graduação em Enfermagem da UFSC. Orientadora do trabalho.

*** Enfermeira. Doutora em Enfermagem. Docente do Departamento de Enfermagem e do Programa de Pós-graduação em Enfermagem da UFSC. Coorientadora do trabalho.

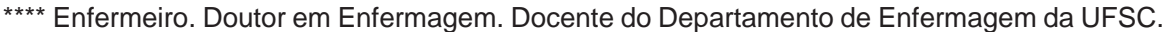
E-mail do autor: 
Cunningham $^{(3)}$ descreve que a primeira hora, imediatamente após o trauma, é um período em que a ressuscitação e a estabilização são consideradas mais benéficas para o paciente, a chamada golden hour. Também encontraram que a morte por trauma tem uma distribuição trimodal:

logo após o acidente: por laceração do cérebro, do tronco cerebral, da aorta, entre outros;

primeiras horas após o acidente - a "golden hour": por hematoma subdural e epidural, hemopneumotórax, laceração do fígado, entre outros;

dias a semanas após o acidente: por sepse e insuficiência de múltiplos órgãos.

De certa forma, foram as guerras que impulsionaram e aprimoraram os serviços de atendimento pré-hospitalar e resgate, em decorrência da necessidade de atendimento rápido e eficaz que garantisse a sobrevivência dos combatentes.

O Dr. Baron Dominique Jean Larrey foi o primeiro a reconhecer a necessidade de uma rápida avaliação de um paciente traumatizado. Durante a Revolução Francesa, veículos eram usados para atender os combatentes feridos e facilitar a avaliação cirúrgica e os cuidados ${ }^{(4)}$. Em 1870, durante a guerra Franco-Prussiana foram relatados os primeiros casos de remoção aeromédica, 160 feridos foram resgatados por balões de ar quente(5). Já em 1908 os irmãos Wilbor e Orville Wright iniciaram seus primeiros vôos com o Zepelin VII, transportando pessoas acidentadas ${ }^{(6)}$.

Durante a Primeira Guerra Mundial (1914 a 1918) as forças sérvias, francesas e americanas utilizaram aviões para remover feridos $^{(7)}$. Em 1918, a Força Aérea Médica Real Britânica formulou e organizou um sistema de transporte para traumatizados. Iniciaram o uso do helicóptero para transporte de soldados feridos durante a Campanha da Somália em 1920. No mesmo ano, na França, foram usados helicópteros especificamente como ambulância,. A Austrália em 1933 contou com seu primeiro serviço aeromédico o Royal Flying Doctor Service ${ }^{(6)}$. Durante a Segunda Guerra Mundial, as Forças Aliadas transportaram cerca de um milhão de pacientes usando serviços de evacuação através de aviões aeromédicos ${ }^{(4)}$.

O uso de helicóptero como um transporte de salvamento foi intensificado a partir de 1940. Em 1944, a direção dos Generais Cirurgiões exigiu que os soldados feridos fossem transportados por helicóptero, promovendo o desenvolvimento deste método de transporte(4). Principalmente de 1939 a 1945, ou seja, durante a II Guerra Mundial houve um grande avanço para a Enfermagem norte-americana, pois os feridos eram removidos em aviões de carga, com três leitos cada, assistidos por flight nurses ${ }^{\mathrm{a}}$. O enfermeiro estava ligado ao Exército e à Marinha, os quais já possuíam cerca de 69.000 destes profissionais. Estes desenvolviam suas atividades como membros das Forças Armadas, no fronte, em hospitais de campanha e nas bases ferroviárias e terrestres ${ }^{(6)}$.

Durante a Guerra da Coréia (1950) e a do Vietnã (19621973), aviões e helicópteros eram usados para evacuação aeromédica do campo de batalha ${ }^{(4)}$. Foi observada uma redução da mortalidade, apesar dos potentes armamentos empregados, sendo isto atribuído a um tratamento definitivo do ferido, efetuado em menor tempo, além do que o helicóptero Bell 205, devido ao seu grande espaço interno, permitiu o tratamento das vítimas em trânsito com técnicas de suporte de vida(7).

Durante a Guerra da Coréia, pode-se observar o reconhecimento dos militares às flight nurses, pois a presença

a Fligt nurses eram enfermeiras especializadas em resgate e remoção aeromédica, nos dias atuais são chamadas de enfermeiras de bordo. Eram treinadas, na época, durante seis meses em hospitais da unidade da Força Aérea. A formação da primeira turma deu-se em 1943, em Kentuchy (Donahue, 1985). do enfermeiro, na região de conflito, era obrigatória; aproximadamente 10000 feridos foram removidos por tais profissionais, através dos helicópteros da marinha. Na Guerra do Vietnã, 5000 enfermeiros serviram, colaborando na remoção de aproximadamente um milhão de pessoas (militares e civis) ${ }^{(6)}$.

O primeiro hospital-base de serviços com helicópteros foi estabelecido no St. Anthony Hospital, em Denver, Colorado, 1972. Em 1984, o Hospital de Aviação (agora Jornal de Transporte Aeromédico) começou transportando, por avião e helicópteros, pacientes de hospitais filiados ${ }^{(4)}$. Atualmente, nos Estados Unidos da América (EUA), existem aproximadamente 250 programas de transporte aeromédico(7).

\section{0 atendimento pré-hospitalar e aéreo no Brasil}

No Brasil, os primeiros registros acerca do serviço de atendimento pré-hospitalar data de 1893, quando o Senado da República aprovou uma Lei que pretendia estabelecer o socorro médico de urgência na via pública, no Rio de Janeiro, no momento capital do país(8).

Um dos programas pioneiros de socorro extra-hospitalar aeromédico foi iniciado em 1988, pelo Corpo de Bombeiros Militar do Estado do Rio de Janeiro, em associação com a Coordenadoria Geral de Operações Aéreas do Estado (CGOA). Sendo que este programa já efetuou 1.300 atendimentos de sua inauguração a julho de $1999^{(7)}$.

O serviço aeromédico no Brasil, especialmente em São Paulo, está ligado à Força Aérea Brasileira (FAB) e à Polícia Militar Estadual, porém esse serviço, destina-se ao resgate e salvamento, eventualmente realiza remoções secundárias, ou seja, inter-hospitalares ${ }^{(6)}$. Estima-se que desde o advento do transporte aeromédico 73.000 a 1.000 .000 de pessoas tenham sido salvas $^{(9)}$.

O serviço pré-hospitalar, desenvolvido no Brasil, atua baseado em duas correntes metodológicas: o sistema europeu e o sistema americano O SAMU tem origem francesa e foi criado por anestesistas intensivistas e emergenciais devido à necessidade da assistência pré-hospitalar, pois os pacientes chegavam ao hospital muitas vezes com piora do caso ou mesmo mortos, por não receberem atendimento precoce e adequado. Este sistema tem como referencial o médico, tanto na Regulação do Sistema, como no atendimento e monitoramento do paciente, até a recepção hospitalar. É um serviço ligado ao Sistema de Saúde, hierarquizado e regionalizado, possuindo comunicação direta com os Centros Hospitalares. Já o sistema norte americano trabalha com paramédicos (com um período de formação de três anos após o segundo grau). Os paramédicos começaram a desenvolver suas atividades nos EUA, devido a Guerra do Vietnã, pois havia necessidade de atendimento médico e como não era possível contar com a presença médica, em todas as frentes de combate, alguns soldados foram treinados para realizarem a assistência necessária No Brasil, a implantação de serviços préhospitalares, municipais e estaduais, vem escolhendo o modelo metodológico de acordo com suas realidades, demandas, perfis, morbi-mortalidade, recursos técnicos, tecnológicos e financeiros ${ }^{(8,9)}$.

\section{Atendimento pré-hospitalar e remoção aérea - reconhecendo uma realidade}

Para o desenvolvimento das atividades assistenciais durante a realização do Trabalho de Conclusão de Curso da Universidade Federal de Santa Catarina, no segundo semestre de 2000 , fez-se a escolha por um serviço de atendimento préhospitalar e remoção aérea, que oferecia as condições necessárias para a realização das atividades previstas, tendo aceitado a realização do trabalho proposto, sendo neste artigo denominado de Empresa.

No Brasil, as normas para o atendimento, em nível préhospitalar, tem sido estabelecidas pelo Ministério de Estado da 
Saúde, através de Portarias regulamentadoras dessa atividade. O Ministério da Saúde considera como nível pré-hospitalar, na área de urgência-emergência, aquele atendimento que procura chegar à vítima nos primeiros minutos após ter ocorrido o agravo à sua saúde, agravo este que possa levar à deficiência física ou mesmo à morte, sendo necessário, portanto, prestar-lhe atendimento adequado e transporte a um hospital devidamente hierarquizado e integrado ao Sistema único de Saúde. A preocupação com o atendimento pré-hospitalar no Brasil começa, portanto, a envolver os profissionais de saúde e os setores governamentais e requer, por ser uma área nova de atuação, a implementação de estudos acerca da adequação dos serviços, sua eficácia e eficiência.

\section{Reconhecendo a estrutura organizacional}

Chiavenato $^{(10)}$ descreve que, administração é o processo de planejar, organizar, dirigir e controlar os esforços dos membros da organização e de utilizar todos os recursos disponíveis para alcançar objetivos organizacionais previamente estabelecidos. Estes recursos incluem o capital, o trabalho, informação e tecnologia.

No planejamento de serviços de saúde, o administrador estabelece suas metas, para possíveis conquistas, necessitando, assim, de dados concretos, para o que a epidemiologia desempenha papel fundamental. Conhecer o perfil do serviço aprofunda a compreensão e amplia a visão do responsável.

O reconhecimento das características da clientela da Empresa foi realizado através do levantamento do perfil do cliente, sendo o mesmo, feito para os três convênios com que a Empresa trabalha, porém só exposto neste artigo o de maior número de clientes (denominado fantasiosamente de UNI). Este levantamento se baseou em uma compilação de dados das fichas de atendimento de dezembro de 1999 a março de 2000, buscando-se o provável diagnóstico de saúde, sexo, idade do cliente e o número de atendimentos realizados. O diagnóstico contido nas fichas de atendimento foram classificados de acordo com a Classificação Internacional de Doenças - CID10.

Constatou-se um total de 6.560 atendimentos da UNI, sendo 3723 (56.7\%) mulheres e 2827 (43.3\%) homens, destes atendimentos 1004 (15.3\%) eram emergências/urgências, a maior incidência foram as doenças do aparelho digestivo 164 (16.3\%), seguido das lesões, envenenamento e outras conseqüências de causas externas, como traumatismos acidentais 161 (16\%) e as doenças do aparelho respiratório 96 (10\%).

A partir do levantamento da faixa etária dos clientes atendidos, pode-se constatar que a maioria encontra-se entre 60 e 80 anos com um total de 300 (29.9\%), seguido de crianças menores de 15 anos 130 (13.0\%). Observamos assim, a necessidade de incrementar a assistência, através da capacitação específica dos profissionais para o atendimento e transporte dessa clientela, reconhecendo suas características, especialmente no tocante as patologias com maior incidência nessas faixas etárias.

Através deste levantamento, observou-se, com maior clareza, a necessidade de qualificação tanto em recursos materiais como humanos, para atender esta demanda com maior eficiência e eficácia.

\section{Recursos Humanos}

Os Serviços de Atendimento Pré-hospitalar e remoção aérea requer uma equipe multiprofissional, geralmente, composta por profissionais da saúde como médico, enfermeira, auxiliar de enfermagem e outros profissionais, como motorista e piloto, para atuação nas unidades móveis, bem como outros profissionais para atuação na base. Cada membro da equipe multiprofissional possui uma função, devendo trabalhar em conjunto, visando um só objetivo, ou seja, o atendimento sistematizado, dinâmico e com qualidade ao cliente e sua família. A composição desta equipe, entretanto, varia de situação para situação, dependendo da capacidade e tipo de serviço disponibilizado. Todavia, independente disso, a chave para o sucesso do serviço de atendimento pré-hospitalar e remoção aérea é a seleção e o treinamento da equipe de saúde ${ }^{(11)}$.

O serviço de atendimento pré-hospitalar pode ser constituído por uma ou mais unidades de atendimento, dependendo da população a ser atendida. Por unidade, entende-se uma ambulância dotada de equipamentos, materiais e medicamentos, guarnecida por uma equipe de, pelo menos, dois profissionais, treinados para oferecer suporte básico de vida sob supervisão e condições de funcionamento pré-hospitalar.

A Empresa era particular, fundada em 1995, com sede na região sul do Brasil, com um total de 350.000 clientes cadastrados, possuindo 2 bases terrestres e 1 aérea, tendo um total de 18 ambulâncias simples, 5 ambulâncias UTI's e 1 aeronave (Citation 1). Seu quadro de pessoal consta de 1 enfermeira (Supervisora Geral), 10 equipes diárias de auxiliar ou técnico e motorista (sendo que todos os motoristas estavam fazendo curso de socorrista) para as ambulâncias simples e 5 destas equipes no período noturno, além de 3 a 4 equipes diárias e noturnas de médicos e técnicos (quando possível a enfermeira) para as ambulâncias UTI, e o médico regulador.

\section{Recursos Materiais}

A administração dos recursos materiais e equipamentos tem como objetivo, garantir as propostas da empresa e um atendimento adequado de qualidade e livre de riscos. As atividades dos administradores em relação aos materiais e equipamentos de uma empresa são a previsão, a aquisição, transporte, recebimento, armazenamento, conservação, distribuição e controle.

A Empresa em questão, não mantém estoque de materiais e medicamentos em grande quantidade, já que sua demanda assim não o requer. Entretanto, percebeu-se que o controle dos mesmos precisava ser reorganizado. Para tanto adotou-se o recurso do check list ${ }^{\mathrm{b}}$, a partir dos já existentes, da elaboração dos kits (kit sutura/pequena cirurgia e kit sondagem vesical) e da revisão da maleta de PCR. Para as ambulâncias simples estabeleceu-se check lists uniformes; já para as UTIs estes divergiram em alguns pontos, devido aos equipamentos diferentes que estas requerem, assim como o check list da aeronave.

\section{Esterilização e desinfecção de materiais e equipamentos}

As condutas para esterilização e desinfecção de artigos e superfícies em serviços de saúde são normatizadas pela Portaria n. 930/1992, que trata do controle de infecção hospitalar, definindo métodos e produtos químicos para limpeza, desinfecção e esterilização(12). A esterilização é o processo de destruição de todas as formas de vida microbianas (bactérias nas formas vegetativas esporuladas, fungos e vírus) mediante a aplicação de agentes físicos e químicos.

A limpeza deve ser realizada com água e sabão ou detergente, em superfícies fixas, promovendo a remoção da sujeira e do mau odor e reduzindo a população microbiana. Segundo o Ministério da Saúde ${ }^{(12)}$, a limpeza de artigos poderá ser feita por qualquer das seguintes alternativas: fricção mecânica, utilizando água e sabão, auxiliada por esponja, pano,

\footnotetext{
b Os check lists são as listagens de todos os materiais de consumo e permanente, como também as medicações das ambulâncias e farmácia. Nestes estão descritos a discriminação do material, a quantidade e a validade. São utilizados para controle destes produtos, como também para averiguação das validades
} 
ou máquina de limpeza com jatos de água quente e detergente, ou ainda, máquinas de ultra-som com detergente/ desencrostantes.

Já a descontaminação de artigos poderá ser feita por qualquer uma das seguintes alternativas ${ }^{(12)}$ : fricção auxiliada por esponja, pano, escova, embebidos com produtos para esta finalidade, ou imersão completa do artigo em solução desinfetante acompanhada ou não de fricção com escova/ esponja, ou pressão de jatos d'água com temperatura entre 60 e 90 graus centígrados, durante 15 minutos (máquinas lavadoras sanitizadoras, esterilizadoras de alta pressão, termodesinfetadoras e similares), ou imersão do artigo na água em ebulição por 30 minutos, ou autoclavagem prévia do artigo ainda contaminado, sem o ciclo de secagem.

$\mathrm{Na}$ Empresa os materiais antes de serem enviados à esterilização são submetidos ao processo de limpeza, sendo desconectados, escovados, lavados e colocados em detergente enzimático. Este tipo de detergente biodegradável é composto por enzimas e surfactantes não-iônicos (de pH neutro), destinados a digerir e dissolver sangue, fezes, entre outros. Após, o material é lavado em água corrente e seco com pano limpo, exceto os intermediários que são secos com ar comprimido. A esterilização do material do Serviço é realizada por uma empresa terceirizada, que emprega óxido de etileno.

Os materiais e superfícies que não são encaminhados para a esterilização sofrem o processo de desinfecção, o qual, consiste em um processo de destruição de microorganismos em forma vegetativa, mediante aplicação de agentes físicos ou químicos. Artigos e superfícies fixas com presença de matéria orgânica devem sofrer este processo. A desinfecção pode darse por agentes físicos ou químicos ${ }^{(13)}$.

\section{Reconhecendo a importância do papel do Enfermeiro}

A partir dessa experiência constatou-se a importância do profissional Enfermeiro na área de emergência préhospitalar e remoção aeromédica como um todo, apesar de ainda ser uma área incipiente de atuação profissional.

O profissional desta área deve demonstrar equilíbrio emocional e domínio técnico adequado, mesmo em situação de estresse. Devido, ao fato da equipe trabalhar em um campo restrito, muitas vezes em condições inadequadas (espaço, tempo, equipamento e materiais), observou-se que há necessidade dos profissionais de serviços pré-hospitalares passarem por uma formação adequada, realizarem programa de educação em serviço e reciclagens na área e terem conhecimento específico destas atividades.

A formação de enfermagem deveria contemplar temas relativos ao atendimento pré-hospitalar e a remoção aeromédica como parte do currículo de nível médio, da graduação e da pós-graduação uma vez que estes campos de trabalho estão ganhando lugar no mercado e os profissionais precisam estar preparados para esta demanda. Além disto, estudos tem demonstrado uma redução da mortalidade provocada por aquelas causas cujo atendimento adequado e rápido pode garantir a sobrevivência (como infarto agudo do miocárdio, traumatismo crânio encefálico), apontando para um serviço em expansão em todo o mundo. As especificidades de serviços dessa natureza requerem, inclusive, que os profissionais estejam preparados, inclusive no tocante a administração de recursos materiais e recursos humanos.

O campo de atendimento pré-hospitalar no Brasil está em expansão, tendo em vista, inclusive, os elevados índices de mortalidade e morbidade ligados as causas externas, a maior incidência de doenças agudas do aparelho respiratório e circulatório. Esta realidade impõem à Enfermagem um desafio no sentido de cobrir uma demanda em expansão, com competência técnica e conhecimentos específicos, a fim de garantir uma assistência pré-hospitalar e remoção aeromédica capaz de contribuir com a sobrevida e redução de seqüelas.

\section{Referências}

1. Ferreira $\mathrm{ABH}$. Novo dicionário Aurélio da língua portuguesa. $2^{\mathrm{a}}$ ed. Rio de Janeiro: Nova Fronteira; 1986. 1838 p. Emergência; p. 634.

2. Nazário NO. Fragmentos de uma construção do assistir em situações de emergência/urgência. Florianópolis (SC): Insular; 1999. 134 p.

3. Cunningham P, Rutledge R, Baker CC, Clancy TV. A comparision of the Association of Helicopter and Ground Ambulance Transport with the Outcome of Injury in Trauma Patients Transport from the Scene. Journal of Trauma, Baltimore (MD)1997 Dec;43(6):940-6.

4. Brink LW, Neuman B, Wynn J. Air transport. Pediatric Clinics of North America, Philadelphia (PA) 1993 Apr;40(2):439-56.

5. Thomaz RR, Miranda MFB, Souza GAG, Gentil RC. Enfermeiro de bordo: uma profissão no ar. Acta Paulista de Enfermagem, São Paulo 1999 jan/abr;12(1):86-96.

6. Gentil RC. Aspetos históricos e organizacionais da remoção aeromédica: a dinâmica da assistência de Enfermagem. Revista da Escola de Enfermagem da USP, São Paulo 1997 dez;31(3):452-67.

7. Santos RR, Canetti MD, Ribeiro Júnior C, Alvarez FS. Manual de socorro de emergência. São Paulo: Atheneu; 1999. 369 p. il.

8. Cardoso MM, OLIVEIRA, A. C. MARTUCHI, S. D., ONIMARU, A. T. Organização dos sistemas pré-hospitalares e salas de reanimação. São Paulo (SP); 2000. Documento interno do SAMU Vale do Ribeira.

9. Peniston-Feliciano H. Aeromedical transport. Delaware Medical Journal, Wilmington (DE) 1995 June;67(6):340-5.

10. Mafra A, Coan ICM, Ribeiro PPWE. Assistência de enfermagem préhospitalar emergencial e em situações de violência: promoção da saúde através do cuidado/educação. [Monografia de Graduação em enfermagem] Florianópolis (SC) Uiversidade Fedral de Santa Catarina, Centro Ciências da Saúde.1999. 120f.

11. Chiavenato I. Administração nos novos tempos: os novos horizontes em administração. São Paulo: Makron Books do Brasil; 1999. 710 p.

12. American Academy of Pediatrics Committee on Hospital Care: guidelines for air and ground transportation of pediatric patients. Pediatrics, Evanston (IL) 1986 Nov;78(5):943-50.

13. Ministério da Saúde (BR). Coordenação de Controle de Infecção Hospitalar. Processamento de artigos e superfícies em estabelecimentos de saúde. $2^{a}$ ed. Brasília (DF); 1994. 49 p.

Data de Recebimento: 18/07/2003

Data de Aprovação: 20/03/2004 